\title{
DEVEMOS CONTINUAR A ESCREVER HISTÓRIAS DA LITERATURA?'
}

- HANS ULRICH GUMBRECHT

Tradução de Caio Cesar Esteves de Souza

\section{RESUMO}

Neste ensaio, Hans Ulrich Gumbrecht busca responder à questão proposta no título por meio de cinco passos. Primeiramente, ele apresenta uma breve história do surgimento dos estudos literários como um campo do saber. Em seguida, descreve o aparecimento da história literária como uma possibilidade discursiva. No terceiro passo, demonstra de que maneira a era de ouro da história literária, em fins do século XIX, coincide com o surgimento da teoria literária como uma subárea acadêmica. No quarto passo, demonstra como as últimas décadas do século XX colocaram em xeque o tipo de historicidade que estava na base das histórias literárias produzidas até então, o que nos leva de volta, na última parte deste ensaio, à questão: nesse contexto, devemos continuar a escrever histórias da literatura?

Palavras- chave: história literária, teoria literária, crise da representação

\section{ABSTRACT}

Hans Ulrich Gumbrecht's essay aims to answer the title question through five steps: first, it presents a brief history of the emergence of literary studies as an academic discipline; secondly, it describes how literary history emerged as a discursive possibility; thirdly, Gumbrecht demonstrates how the golden age of literary history towards the end of nineteenth century coincides with the emergence of literary theory as a subfield of literary studies as a discipline. On the fourth step, the author demonstrates how, during the final decades of twentieth century, the very type of historicity that was the basis of literary history was questioned, which leads us back to the last part of this essay: in that context "shall we continue to write histories of literature?"

Keywords: literary history, literary theory, crisis of representation 
$\mathrm{O}$ título deste ensaio parece anunciar a repetição do que eu considero ser um dos piores hábitos nos estudos literários e nas humanidades em geral. Ele pode de fato parecer uma daquelas questões autorreferenciais que os críticos gostam de propor - com a promessa implícita de chegar às respostas mais reconfortantes, respostas essas, para piorar as coisas, cujo mérito parece crescer graças à pretensão de se ter aberto, por um momento, a visão para um futuro preocupante. Certamente, posso garantir que a minha questão tem uma intenção muito mais direta e produzirá predições muito menos otimistas - por uma série de motivos. Em primeiro lugar, acredito que as humanidades estão subsistindo - em vez de existindo — hoje em um ambiente institucional, econômico, político e até mesmo cultural no qual certas questões que costumavam ser "meramente retóricas" podem ter se transformado, pelas nossas costas, em questões perfeitamente sérias e de fato ameaçadoras. Nesse sentido, e em segundo lugar, temos todos os motivos para prestar atenção ao fato, em si mesmo banal, de que todas as instituições - entre elas, as disciplinas acadêmicas em que estamos trabalhando - tiveram suas origens históricas e, portanto, deixarão de existir um dia. Isso é especificamente óbvio, em terceiro lugar, no caso de uma disciplina como a nossa, cuja origem histórica, como tentarei demonstrar, foi particularmente improvável. Afinal, quer estejamos dispostos a assumi-lo em público ou não, os críticos literários sabem muito bem que a humanidade sobreviveria com tranquilidade sem a crítica literária - e, provavelmente, mesmo sem as humanidades em geral.

Com essas observações iniciais um tanto francas, espero, já tracei a estrutura da discussão a partir da qual tentarei lidar com a minha tarefa, ou seja, a partir da qual discutirei a questão sobre o que podemos e o que devemos fazer, nas condições atuais, com a herança cultural e discursiva da "história literária". Mais precisamente, minha reação terá cinco partes. Eu começarei com uma descrição (I) bastante breve do surgimento histórico, no início do século XIX, dos estudos literários como uma disciplina acadêmica, cuja forma institucional inicial, é importante ressaltar, ainda não continha a subárea da "história literária". Com base nisso, demonstrarei como, após algumas décadas e no contexto epistemológico ao qual nos referimos, desde Michel Foucault, como "a crise da representação", a história literária surgiu como uma fascinação intelectual específica e como uma possibilidade discursiva (II). Na terceira parte, central nesta narrativa, falarei sobre a situação dos estudos literários em fins do século XIX, quando, paradoxalmente, uma primeira crise de sua forma institucional não apenas provocou o surgimento da teoria literária como uma nova subárea da disciplina, mas também inaugurou uma era de ouro da história literária por meio de uma notável proliferação de novas perspectivas e questões (III). No passo subsequente (IV), proporei que o próprio tipo de historicidade que esteve na base do surgimento da história literária no início do século XIX deixou de existir nas últimas décadas do século XX. 
[2] Para versões mais detaIhadas e historicamente documentadas da narrativa a seguir, vejam meus ensaios: "'Un souffle d'Allemagne ayant passé': Friedrich Diez, Gaston Paris and the Genesis of National Philologies", Romance Philology 40, n. 1, pp. 1-37, 1986; "História da Literatura: fragmento de uma totalidade perdida", in Histórias da literatura: as novas teorias alemãs, Heidrun Krieger Olinto (ed.), São Paulo: Editora Ática, 1996, pp. 223-40; prefácio, em coautoria com Jeffrey Schnapp, de Medievalism and the Modernist Temper, R. Howard Bloch e Stephen G. Nichols (ed.), Baltimore: Johns Hopkins University Press, 1996, pp. 475-81.
Essa tese, obviamente, nos levará de volta à nossa questão inicial, final e bastante séria (V) - nos conduzirá de novo à questão sobre o que devemos fazer, hoje, com o legado intelectual e institucional da história literária.

Embora seja verdade que existiram múltiplas maneiras de lidar com textos chamados "literários" desde a época do helenismo, proponho que não identifiquemos essas práticas sobretudo filológicas como os primórdios históricos da "crítica literária", pois elas não se relacionam com o nosso presente por nenhuma continuidade institucional ou intelectual. Uma argumentação consistente pode ser desenvolvida para demonstrar que a nossa tradição remonta a uma série de universidades alemãs (mais precisamente, prussianas) na segunda e na terceira décadas do século XIX2. O contexto sócio-histórico mais amplo para esse desenvolvimento foi uma tensão crescente, no início dos estados "burgueses" pós-revolucionários ou pós-reformas, entre uma imagem nova e normativa da sociedade e das relações sociais propagadas por esses estados, por um lado, e, por outro, a experiência cotidiana dominante nas sociedades de então, a qual estava frustrando as expectativas daquelas promessas eufóricas. Como um domínio de mediação e compensação nesse conflito, uma esfera de lazer não mais específica de apenas uma classe social começou a se estabelecer onde, sob condições institucionais de ludicidade e ficção, todas aquelas novas promessas implícitas à imagem normativa da sociedade eram "mantidas" "feitas verdadeiras". Se, por exemplo, igualdade de oportunidade, que era um dos valores fundamentais dos novos estados, estava longe de ser encontrada na realidade cotidiana, algumas formas de lazer a ofereciam como uma experiência ilusória.

Ora, temos vários motivos empíricos para acreditar que a escrita literária e, sobretudo, a leitura literária desempenharam um papel fundamental no cerne da instituição do lazer no início do século XIX. Esse papel de fato pode explicar o interesse do Estado prussiano em promover e financiar uma disciplina acadêmica (isto é, os estudos literários na forma de Germanistik) cuja função inicial era desenvolver uma cultura nacional e uma forma de ler por meio das quais a nova função mediadora da literatura no contexto do lazer seria garantida e que, além disso, usaria textos literários como repertório para ilustração e exemplificação de uma imagem normativa igualmente nova da sociedade. Durante as décadas seguintes, os estudos literários começaram a se desenvolver, no contexto europeu mais amplo e norte-americano, sob duas premissas estruturais diferentes e em duas formas institucionais diversas. Onde quer que a nova sociedade burguesa se visse como o resultado de uma revolução vitoriosa, como ocorreu na Grã-Bretanha, na França e nos Estados Unidos, o horizonte normativo de referências com o qual as experiências cotidianas tinham de ser mediadas na leitura de literatura 
consistia de conceitos abstratos e tendenciosamente meta-históricos no mesmo tom de liberté, egalité, fraternité. Havia um hábito predominante, nesse contexto, de ler textos literários como alegorias daqueles conceitos e valores abstratos, e os primeiros protagonistas da nova disciplina — por exemplo, Matthew Arnold, na Inglaterra, e Paulin Paris, na França — tiveram uma função pública mais próxima de pedagogos palestrantes do que de acadêmicos altamente especializados (antes de virarem professores, Arnold havia sido inspetor na educação secundária, e Paris havia trabalhado como bibliotecário).

No entanto, naqueles contextos nacionais em que as reformas burguesas tinham sido tomadas como uma reação a uma experiência de derrota nacional e humilhação, como nos países germânicos e, posteriormente, na Itália, na Rússia ou na Espanha, o horizonte normativo da sociedade foi tipicamente ocupado por uma imagem idealizada do passado de cada nação, condição essa que produziu uma lógica que tornou necessário aos textos literários serem apresentados e lidos como documentos que ilustravam esse passado glorioso. Foi assim que acadêmicos, mais do que pedagogos, como Jacob e Wilhelm Grimm usaram suas habilidades filológicas altamente desenvolvidas. Porém, embora a ênfase em seus trabalhos com textos individuais fosse sempre a historicização, a maior parte desses acadêmicos não estava interessada em escrever histórias de suas literaturas nacionais.

\section{II}

Mesmo no contexto prussiano dos primeiros estudos literários, e apesar de sua inclinação forte e bastante sofisticada à historicização, a "história literária" não se tornou uma preocupação e uma forma discursiva antes do advento da crise epistemológica, no segundo quartel do século XIX, que Foucault descreveu sob o nome de crise de la représentation. Tomando emprestado um conceito central da filosofia de Niklas Luhmann (conceito esse, aliás, que o próprio Luhmann nunca usou de maneira estritamente histórica), proponho me referir a essa mesma síndrome histórica como o"surgimento do observador de segunda ordem"3. A posição do observador de segunda ordem, conforme se tornou uma realidade institucional na cultura ocidental durante o século XIX, é um papel no qual aquele que observa o mundo não pode deixar de se observar no ato da observação. É o papel da autorreflexividade, como provavelmente esteve disponível, no estatuto de uma opção, para todas as culturas humanas de todos os tempos, mas que agora se transformou em uma instituição, em uma lei estrutural.

Como condição nova e inevitável para qualquer tipo de apropriação do mundo, o surgimento do observador de segunda ordem teve uma série de consequências na epistemologia e na cultura do século XIX, entre as quais se encontra a que nos interessa aqui e que podemos chamar de "perspectivismo".
[3] Para maiores detalhes históricos e precisão conceitual sobre a emergência do observador de segunda ordem, ver meu ensaio "Cascais de Modernização", in Interseções: a materialidade da comunicação, João Cézar de Castro Rocha (ed.), Rio de Janeiro: Imago / UERJ, 1998, pp. 23-39. 
Um observador que se observe no ato de observação descobrirá que a sua percepção e experiência do mundo dependem da sua perspectiva (no sentido literal e metafórico, simultaneamente); essa descoberta o leva rapidamente à percepção de que, para cada objeto de referência ao mundo, há formas potenciais de experiência, de conhecimento ou de representação à proporção que há perspectivas de observadores. A consequência potencial mais extrema que pode decorrer dessa proliferação de perspectivas é, evidentemente, o medo do desaparecimento (ou, ainda, da não existência) de quaisquer "objetos de referência" fora do próprio observador do mundo.

Eu creio que, desde os anos 1820, uma mudança na representação do mundo - de um modelo de espelho ("um para um") para um princípio narrativo — se tornou simultaneamente uma solução bem-sucedida e duradoura para esse problema e a base para o que chamamos desde então de "historicismo do século XIX". Mas como a historicização poderia se tornar uma solução para as ameaças do perspectivismo? Isso ocorreu porque um discurso no qual uma nação é identificada por sua história, ou no qual uma espécie é identificada por sua evolução, será sempre capaz de integrar, em uma sequência narrativa, (a potencial infinidade de) suas diferentes representações. Nesse mesmo contexto, tornou-se plausível não apenas usar textos literários individuais como "evocações" pontuais de um passado nacional glorioso, mas também ver nas histórias das literaturas nacionais, como objetos intencionais e formas discursivas em seu próprio direito, uma fórmula e até mesmo um caminho principal que daria acesso à verdadeira compreensão da identidade de uma nação.

No contexto alemão (principalmente, mas com certeza não exclusivamente), as possibilidades formais da história literária como um discurso parecem ter se desenvolvido, desde meados do século XIX, entre duas possibilidades opostas. Não é surpreendente que houvesse um tipo de história literária fortemente teleológica, visivelmente hegeliana, que tentou moldar a história das literaturas nacionais como uma trajetória rumo à autorrevelação da identidade nacional. Os escritos de Georg Gottfried Gervinus e, várias décadas depois, os de Wilhelm Scherer tentaram explorar essa possibilidade. $O$ outro estilo poderia ser caracterizado como "antropologia histórica" e usava diferentes tipos e formas de litera-

[4] Ver, de Georg Gottfried Gervinus, Geschichte der poetischen National-Literatur der Deutschen. Leipzig: Engelmann, 1942; de WiIhelm Scherer, Geschichte der deutschen Literatur. Berlin: Weidmann, 1883; e de Gustav Freytag, Bilder aus der deutschen Vergangenheit. Leipzig: Hirzel, 1863. tura de diferentes momentos do passado nacional para constituir uma imagem complexa da nação em questão, sem haver uma tese central sobre a identidade nacional ou uma ideia de seu desdobramento sistemático. Os livros de Gustav Freytag sobre a cultura alemã (e, provavelmente, aqueles escritos pela maior parte dos novos historiadores literários de então) pertenceram a essa variedade. ${ }^{4}$

Ora, ao lado de formações discursivas do historicismo, e parcialmente entre elas, uma estrutura complexa de imaginar o tempo e, por meio disso, de vivenciar transformações surgiu e foi tão universalmente aceita que as pessoas logo tenderam a confundi-la com a "consciência histórica", na mesma condição 
meta-histórica. ${ }^{5}$ Sua característica mais básica foi a assimetria entre um futuro aberto, vivido como horizonte de expectativas, e um passado que o tempo presente, a cada momento, parecia deixar para trás como um espaço fechado de experiência. Entre aquele futuro e esse passado, o presente parecia ser, como Charles Baudelaire disse certa vez, "um momento imperceptivelmente breve de transição", um momento de transição que também parecia ser uma condição necessária para a existência do "sujeito" e de suas funções específicas. Pois era esperado que o papel do sujeito, naquele curto presente, fosse adaptar a experiência do passado às condições do presente e projetá-la para o futuro como expectativa. A topologia na qual todos esses aspectos se uniram foi a de um progressivo movimento que constantemente deixava o passado para trás para cruzar os limiares sempre renovados entre o presente e o futuro.

Da perspectiva de nosso assunto, um ponto importante de se compreender é que, desde o surgimento do observador de segunda ordem e, subsequentemente, do historicismo do século XIX, todo texto literário havia se tornado um elemento em potencial para potenciais histórias de literaturas nacionais. $O$ uso dessa possibilidade dependeu principalmente de contextos políticos mais amplos. De fato, isso ocorreu — ou seja, histórias de literaturas nacionais se tornaram uma instituição - em qualquer lugar ou momento em que uma nação passou por um período de derrota e humilhação nacional. No caso francês, por exemplo, podemos associar o início dessa instituição com o exato momento da derrota do país na Guerra Franco-Prussiana de $1870-71 .{ }^{6}$ Mas houve outras nações, a Inglaterra, por exemplo, ou os Estados Unidos, nas quais, pela mesma razão (ou, mais precisamente, pelo motivo oposto, ou seja, pela falta de um momento de derrota nacional) ${ }^{7}$, a história literária nunca se tornou de fato uma opção discursiva para a crítica literária. Seria interessante investigar sob quais horizontes específicos de autorreferência nacional se deu o projeto de Antonio Candido de reconstruir a "formação da literatura brasileira".

\section{III}

Sem qualquer dúvida, o século XIX foi a época mais feliz para a crítica literária em geral e a história literária em específico, pois foi o momento em que, como disse Wolfgang Iser certa vez, se a literatura tendia a desempenhar a função de uma religião nacional, nossa disciplina servia como a sua teologia. Com essa forma e estatuto, a crítica literária sofreu sua primeira crise em fins do século XIX, mas essa crise se mostrou produtiva em dois sentidos. Ela causou, em primeiro lugar, o surgimento da "teoria literária" nos limites da crítica literária, e produziu, em segundo, por meio da história literária, uma série de novas questões e preocupações que se tornaram uma motivação para o experimento, desde o início do século XX, com diferentes formas discursivas e novas funções para a história literária.
[5] A descrição detalhada e a re-historicização desse conjunto de questões podem ser consideradas o grande feito em vida de Reinhart Koselleck. Ver, sobretudo, os ensaios que compõem o volume Vergangene Zukunft: Zur Semantik geschichtlicher Zeiten. Frankfurt am Main: Suhrkamp, 1979.

[6] Ver meu ensaio "Gaston Paris en 1871", in Le Moyen Âge de Gaston Paris, Michel Zink (ed.), Paris: Jakob, 2004, pp. 69-80.

[7] Curiosamente, nesse sentido, os primeiros impulsos rumo a uma preocupação séria com a história da literatura em universidades americanas vieram apenas nas décadas de 1960 e 1970 (com o trabalho de Michel Foucault como principal inspiração) - o que significa que a história literária nos Estados Unidos surgiu no momento de depressão nacional após a Guerra do Vietnã. 
[8] Ver meu ensaio "The Future of Literary Studies?", in New Literary History, 26, n. 3, pp. 499-519, 1995 Tradução para o português em meu livro Corpo e forma. Rio de Janeiro: EDUERJ, 1997.
Creio que o que causou essa crise na disciplina foi um crescente ceticismo em relação ao estatuto tradicionalmente ontológico daqueles conceitos e imagens que, desde o fim do século XVIII e o início do XIX, tinham ocupado os horizontes normativos de diferentes sociedades e nações como quadros de referência para os primeiros momentos institucionais de nossas disciplinas. De repente, valores como aqueles condensados nos conceitos morais da tradição iluminista, ou o estatuto de realidade de imagens romanticamente idealizadas de diferentes nações, não eram mais tão óbvios e plausíveis quanto haviam sido durante quase um século - e esse processo de desvalorização emocional e ontológica foi intensificado de fato exponencialmente pelo impacto da Primeira Guerra como uma crise existencial (quase tanto para as nações vitoriosas quanto para as derrotadas). Se a crítica literária perdeu o seu horizonte de referência original nesse processo, uma nova série de questões autorreflexivas e de preocupações sobre a disciplina emergiu e, desde então, passou a mapear a "teoria literária" como uma nova subárea. ${ }^{8} \mathrm{Se}$, durante o século XIX, a mediação entre um conceito normativo de sociedade e a sua realidade cotidiana tinha sido o quadro de referência para os estudos literários, veio à tona a questão, como um primeiro questionamento para a teoria literária e no contexto de um crescente ceticismo em relação àquele horizonte de referência, sobre qual deveria ser a função e a atribuição autodeterminada da crítica literária. Pois, se, durante o século XIX, qualquer texto que pudesse ser submetido à função mediadora da crítica literária era chamado de "literatura", surgiu o problema, de repente, de haver possibilidade de uma definição coerente e, talvez, até meta-histórica e transcultural, de "literatura" (essa preocupação parece ter movido diferentes teorias literárias desde suas primeiras materializações, isto é, desde o surgimento do Formalismo Russo durante os anos que antecederam à Primeira Guerra Mundial e à Revolução de Outubro). Outra questão de "teoria literária", em meio a uma potencial infinidade de novas preocupações, tentaria determinar o estatuto da história da literatura em relação a outras "séries históricas" (como os formalistas costumavam dizer), isto é, a história da música ou da arte, mas também a história política ou econômica.

Para a história literária, especificamente, essa crise decerto ainda não estava acompanhada por uma perda completa da crença em seus diferentes poderes explicativos. Em vez disso, o que parecia estar afetado era a "naturalidade" em que, desde suas bases românticas e, mais explícita e decididamente, desde o surgimento do observador de segunda ordem, a historicidade da literatura e os discursos de história literária tinham sido tomados como principal caminho rumo a diferentes identidades nacionais. A crise da crítica literária e o surgimento da teoria literária produziram uma nova preocupação ainda mais complexa sobre os diferentes percursos em que a identidade fenomênica e discursiva da "literatura" determinaria suas possibilidades específicas de compreensão e percepção históricas. Se a produtividade de uma certa ingenuidade que acompanhou as histórias 
literárias durante o século XIX tinha desaparecido definitivamente, uma nova precisão na reflexão sobre o estatuto da história literária e no uso de seu potencial epistemológico surgiu como uma compensação por essa perda. Como consequência, podemos observar, desde o início até quase o fim do século $X X$, uma ampla gama de novas reflexões e novas práticas surgindo ao mesmo tempo em discursos de teoria literária mais teleológica ou antropologicamente inspirados.

Um dos primeiros e mais influentes desses discursos foi a tentativa de Georg Lukács, na Teoria do romance (1920), de determinar o que ele dizia ser a relação específica entre literatura e processo da história, com base numa reflexão sobre a forma literária. Para Lukács, a característica principal do discurso da literatura, sobretudo em comparação com o da historiografia, era a sua concretude e, portanto, o seu poder ilustrativo. Graças a isso, ele acreditava que a literatura era capaz de identificar certas regularidades em certas "leis" da mudança histórica antes e com maior profundidade do que os historiadores mais ousados intelectualmente - $\mathrm{e}$, com frequência, contrariamente às diversas orientações políticas dos historiadores literários. O exemplo favorito de Lukács era a profunda compreensão de Balzac, um monarquista, do mundo capitalista e da maneira como ele tomava forma no início do século XIX. Do mesmo modo, pode-se tentar estabelecer uma associação entre uma dimensão redentora em nossa abordagem do passado (da qual Walter Benjamin, uma década depois, falou em suas "Teses sobre a Filosofia da História"9) e, por outro lado, uma capacidade específica dos textos literários de evocar mundos há muito desaparecidos. "História da recepção", desde o fim da década de 1960, foi o sonho acadêmico de identificar o impacto da literatura nas mudanças do mundo por meio da mediação de seu impacto nos leitores. Com o estudo histórico da literatura como um meio, finalmente um novo movimento surgiu durante a década de 1980, propondo-se estabelecer uma conexão com uma ideia de evolução da humanidade na qual a história da tecnologia aparece como uma continuação da evolução biológica com significados distintos..$^{10}$

No amplo paradigma discursivo que caracterizei como "antropologia histórica", eu colocaria, por exemplo, a obra-prima de Erich Auerbach, Mimesis, pois ela tenta ilustrar como o "realismo literário", desde o início da era cristã, tem sido a convergência paradoxal entre o nível mais "humilde" do decoro discursivo (sermo humilis) e o conteúdo mais sublime da existência humana, isto é, o sabor trágico de seu cotidiano. ${ }^{11}$ Apenas dois anos após a publicação do livro de Auerbach em 1946, Ernst Robert Curtius disse ter documentado, em seu trabalho monumental Literatura Europeia e Idade Média Latina, como a presença contínua de certo repertório de formas retóricas e literárias criou um enraizamento da cultura ocidental moderna em uma tradição milenar, muito necessária na desoladora situação existencial que se estabeleceu após a Segunda Guerra Mundial. ${ }^{12}$ Inadvertidamente retornando a uma prática que lembra as primeiras historiografias literárias da época do romantismo, tem havido uma tendência, desde as décadas de 1970 e
[9] Walter Benjamin, "Theses on the Philosophy of History", in Illuminations, Hannah Arendt (ed.), Nova York: Schocken, 1968, pp. 253-64.

[10] Friedrich Kittler, Discourse Networks 1800 / 1900. Stanford, CA: Stanford University Press, 1990; e Hans Ulrich Gumbrecht e K. Ludwig Pfeiffer, eds., Materialities of Communication. Stanford, CA: Stanford University Press, 1994.

[11] Erich Auerbach, Mimesis: The Representation of Reality in Western Literature. Princeton, NJ: Princeton University Press, 1953. 
[12] Ernst Robert Curtius, European Literature and the Latin Middle Ages. Nova York: Pantheon, 1953.

[13] Ver, como documentação para trabalhos nessa direção produzidos sobretudo no Brasil, José Luís Jobim (ed.), Literatura e identidades. Rio de Janeiro: Universidade do Estado do Rio de Janeiro, 1999.

[14] Michel Foucault, "What is an Author?”, in Language, Counter-Memory, Practice, Donald F. Bouchard (ed.), Ithaca, NY: Cornell University Press, 1977, pp. 113-38.
80, de usar a história literária como um meio de rastrear e produzir identidade. ${ }^{13}$ Embora Mikhail Bakhtin, com os conceitos de "carnavalização" e "diálogo", e Iser, com o conceito de "ficção", tenham tentado oferecer topoi de convergência e de comparação para abordagens da literatura que buscavam acima de tudo ilustrar a variação histórica em um quadro estável de condições, o famoso ensaio de Foucault "O que é um autor?" se destaca e se torna uma motivação para a tendência oposta, isto é, para o mais sofisticado e rigoroso tipo de historicização conceitual na análise da literatura e de suas instituições. ${ }^{14}$ Foi sobretudo graças a esse esforço de diferenciação histórica extrema que, durante os anos 1980 e 90, a possibilidade de construir um conceito de literatura verdadeiramente meta-histórico e transcultural, como a teoria literária quisera fazer desde suas origens no século XX, tornou-se alvo de um crescente ceticismo. Pois a nova intensidade na prática da historicização começou a problematizar o conceito meta-histórico de "literatura" que tinha implicitamente dado continuidade a todas as tentativas anteriores de escrever "história literária".

\section{IV}

A minha intenção, na seção anterior, foi mostrar como a crise pela qual a forma e a função da história literária do século XIX passaram se tornou, na virada do século, fonte de uma enorme produtividade intelectual e discursiva. Do ponto de vista da crítica literária como uma instituição, essa proliferação teve um efeito sobretudo centrífugo, um efeito, como vimos, que produziu dúvidas sobre a legitimidade epistemológica de qualquer conceito de "literatura" que fosse capaz de oferecer as bases para uma disciplina acadêmica. Mas, se todos esses problemas foram daqueles que podem se transformar tranquilamente em "méritos intelectuais", nós agora começamos a compreender que, pouco antes do fim do segundo milênio, passamos por um processo de transformação epistemológica que, de uma maneira muito mais profunda e radical, abalou para sempre as premissas em que a "história", como a nossa relação moderna com o passado, esteve baseada.

Estou me referindo ao debate amplamente difundido em que a identificação do presente como "pós-moderno" ou como uma "continuação da modernidade" parece estar em jogo. ${ }^{15}$ No retrospecto atual, e independentemente das emoções (e agressões) políticas que caminharam lado a lado com essa discussão, podemos ver que ela foi frequentemente uma reação confusa a duas mudanças epistemológicas bastante diferentes, mas fundamentais. Ela, sobretudo, marca o fim da crença que resultara do surgimento do observador de segunda ordem como uma solução tornada fundamental para o historicismo do século XIX, o fim da crença de que um princípio narrativo na identificação de fenômenos seria capaz de absorver e, dessa forma, de neutralizar todos os problemas do perspectivismo. Daí vem a insistência, nos primeiros diagnósticos do "momento pós-moderno", inicialmente 
no livro A condição pós-moderna, de Jean-François Lyotard, na inviabilidade de todos os tipos (sobretudo os hegelianos) de grandes narrativas (grands récits). ${ }^{16}$ Complementar a esse ceticismo acerca da historicização como uma ferramenta epistemológica, surgiu uma nova apreciação das qualidades literárias na escrita da história, belamente defendida e ilustrada pelo livro de Hayden White, Meta-histó$\mathrm{ria}^{17}$ - e, posteriormente, foi transformada em um estilo intelectual e acadêmico muito respeitável que veio a se chamar Novo Historicismo. Variações literárias na representação do passado se tornaram lei, já que não mais se afirmavam as verdades referenciais.

A nova questão que autores como Lyotard e White estavam propondo, uma questão que - de certa forma, surpreendentemente — não havia sido feita durante um século e meio, era por que a "grande narrativa" deveria ser mais independente de sua perspectiva do que qualquer descrição menor. Eles também questionaram por que não deveria haver uma infinidade de possíveis narrativas identificando, digamos, a nação letã, já que havia, evidentemente, uma potencial infinidade de definições e imagens para o mesmo objeto de referência. É interessante registrar como essa nova atitude diante do passado coincidiu, ao menos cronologicamente, com uma verdadeira fobia à história e a qualquer forma discursiva que pudesse ser chamada de "narrativa", algo central para o trabalho e notório na persona pública de Jacques Derrida.

Muito mais importante, no entanto, como uma segunda transformação contemporânea no nível epistemológico, foi a mudança pela qual a topologia básica de "história" " "historicismo", como havia surgido no início do século XIX, estava passando. Se e, se sim, de que maneiras específicas a crise dos grands récits e a mudança na topologia de "historicismo" estavam interconectadas é algo que terá de ser trabalhado e discutido em futuras pesquisas e reflexões. Mas está claro que, durante as décadas finais do século XX, ao menos na cultura ocidental, o futuro perdeu aos poucos a qualidade de ser um "horizonte aberto de expectativas" $\mathrm{e}$ se tornou uma área que agora parece ao mesmo tempo inacessível para nossas predições e tendenciosamente pouco atraente para nossos desejos. Ao mesmo tempo, temos incessantemente desenvolvido nossas capacidades tecnológicas e artesanais de preservar e reproduzir artefatos do passado. Portanto, está se tornando possível, quase literalmente, em vez de sempre "deixar o passado para trás", mergulhar, em um sentido bastante material, em mundos que precederam o nosso. Entre um futuro que parece estar fechado e um passado aberto a inundar o nosso presente, o presente começou a se expandir daquele "momento imperceptivelmente breve de transição" para uma ampla dimensão de simultaneidades. ${ }^{18}$ Mas por que essa transformação seria epistemologicamente relevante?
[16] ean-François Lyotard, The Postmodern Condition: A Report on Knowledge, trad. Geoff Bennington e Brian Massumi. Minneapolis: University of Minnesota Press, 1984.

[17] Hayden White, Metahistory: The Historical Imagination in Nineteenth-Century Europe. Baltimore: Johns Hopkins University Press, 1973.

[18] Hayden White, Metahistory: The Historical Imagination in Nineteenth-Century Europe. Baltimore: Johns Hopkins University Press, 1973. 
É epistemologicamente relevante porque o desaparecimento daquele passado estreito da modernidade leva embora a notável posição limiar que costumava ser parte estrutural e condição funcional do que nós chamamos de "sujeito". 0 que está em jogo, portanto, o que explica (e, penso, justifica completamente) a questão do título deste ensaio é a necessidade de repensar nossa relação com o passado em um ambiente intelectual transformado, no qual não podemos mais confiar no "moderno", ou seja, na tradição cartesiana de uma filosofia e de uma epistemologia baseadas no sujeito. Isso é um desafio para as nossas maneiras de vivenciar e pensar o mundo que certamente ultrapassa as fronteiras da cultura histórica ou da história como uma disciplina acadêmica. Isso é um desafio, por fim, em cuja complexidade nossos problemas como historiadores literários parecem comparativamente marginais (e por que simplesmente não dizemos: desimportantes?). Ao apontar para esse desafio, cheguei ao ponto principal que eu queria discutir neste ensaio, ou seja, cheguei à observação de que a principal gama de problemas filosóficos com a qual a escrita de histórias literárias é confrontada hoje vai demandar um esforço muito mais profundo de pensamento e reconsideração que todas as provocações que emergiram desde a proliferação centrífuga, mas absolutamente produtiva, de questões e novos paradigmas na história literária durante o século XX. Hoje torna-se claro que um novo início para a história literária pressuporia uma série de discussões, respostas e soluções que não podem ser produzidas apenas pelos estudos literários.

Novamente, a implicação dedutiva da última sentença — isto é, a de que nós temos de resolver certas questões epistemológicas antes de podermos lidar com problemas disciplinares e discursivos "menores" — não abrange de fato como a vida intelectual nem ao menos como as disciplinas acadêmicas de fato funcionam. A verdade é que hoje já podemos ver historiadores literários trabaIhando eficientemente em busca de soluções "abaixo" do nível epistemológico, em alguns casos até sem ter avaliado e compreendido a magnitude dos problemas filosóficos envolvidos. Começando, contudo, no devido rigor dedutivo, com a

[19] Ver, como um exemplo excelente, o livro de Luiz Costa Lima, História, fição, literatura. São Paulo: Companhia das Letras, 2006. posição indefinida do sujeito como um problema epistemológico ${ }^{19}$, devemos nos perguntar o que exatamente são as novas incertezas que decorrem da diluição do "presente breve", que costumava ser o habitat do sujeito. Eu percebo duas mudanças principais.

Em primeiro lugar, a posição do novo observador vis-à-vis ao mundo realmente não é mais uma posição externa. Não está mais na fronteira entre (e, portanto, duplamente fora do) passado e presente e também não parece estar mais em uma posição fora do mundo dos objetos. Em segundo lugar, se a posição de nosso observador não é mais externa em relação ao mundo dos objetos, então o contraste ontológico tradicional entre um observador cartesiano que era 
todo espírito / consciência e o mundo dos objetos como um mundo puramente material está se tornando difuso e irá, em última instância, desaparecer. O novo "sujeito fragmentado" (essa é a expressão com que Luiz Costa Lima se refere ao mesmo problema) não pode mais ser um sujeito puramente cartesiano, pois isso inclui componentes físicos - somáticos - e, portanto, restabelece um contato sensorial com o mundo dos objetos. É como se, de repente, nos encontrássemos no meio do tempo e em meio aos objetos, com um desejo de nos tornar parte desse mundo material (e, talvez, até de sua temporalidade) - experiência que, pela absoluta falta de familiaridade, é confusa para nós. Em outras palavras, nós temos de aprender o que significa ser um observador que se põe, com o próprio corpo, no meio de um mundo material para ser observado.

Talvez essa situação explique o desejo novo e ainda crescente entre os historiadores e seus leitores (e eu me refiro a um vago, porém poderoso desejo, mais do que a um "paradigma") de mergulhar em mundos passados como mundos materiais. O Memorial do Holocausto, de Peter Eisenman, em Berlim, não é um símbolo nem uma representação do mais violento dos crimes coletivos da história da humanidade. É um campo irregular, de blocos de concreto cinza, capaz de produzir, como os campos de concentração nazistas, sentimentos de terror e de angústia naqueles que por ali caminham. É possível que haja uma afinidade entre esse monumento e alguns experimentos muito mais inofensivos organizados por curadores e autores. Estou falando de experimentos que afetarão, tanto quanto possível, a existência corpórea e emocional de seus visitantes e leitores. ${ }^{20}$ Parece haver um consenso, entre aqueles que realizaram esses experimentos, de que textos "literários" (e eu não vou retornar aqui ao problema infinito / à impossibilidade de definição de "literatura") são particularmente bons em fazer o passado presente; presente como a impressão de um ambiente material e sensorial. Por que isso ocorre? Pode ter a ver com um potencial inerente a muitos textos literários que subestimamos por muito tempo e para o qual estamos nos tornando mais sensíveis sob as condições específicas atuais de autorreferência em que tendemos a achar tudo muito cartesiano (porque às vezes sentimos que não somos nada além da fusão entre consciência e software).

O efeito ao qual me refiro pertence à dimensão estética da literatura e poderia ser chamado de sua "concretude". Uma "concretude" da literatura — não simplesmente no sentido de Lukács, de textos e seus conteúdos ilustrando conceitos abstratos, mas "concretude" como a capacidade de dar aos leitores a sensação de estarem cercados por um mundo material e inscritos na transformação de seus ritmos $^{21}$. Sentimos que estamos envolvidos (e estamos de fato envolvidos) pelos sons do século XVII quando recitamos um soneto de Shakespeare ou versos de Os Lusíadas. Mas até mesmo textos em prosa, como O homem sem qualidades, de Robert Musil, conseguem fazer com que nos sintamos imersos nas atmosferas de seus mundos passados. ${ }^{22}$
[20] Meu próprio experimento nesse sentido foi o livro In 1926: Living at the Edge of Time. Cambridge, MA: Harvard University Press, 1997. Tradução brasileira: Em 1926: vivendo no limite do tempo. Rio de Janeiro: Editora Record, 1999.

[21] Ver meu texto curto "Einladung ins Reich der Sinne: Romanische Konkretion und romanistische Prägnanz", Frankfurter Allgemeine Zeitung, 28 de setembro de 2005.

[22] O conceito alemão que tentei traduzir com "atmosfera" é Stimmung. Vejam o início da série de reflexões em desenvolvimento sobre Stimmung sob o título "Erinnerung an Herkuenfte: Stimmung - ein vernachlaessigtes Thema der Literatur", Frankfurter Allgemeine Zeitung, 30 de novembro de 2005. 
[23] Ver Denis Hollier (ed.), A New History of French Literature. Cambridge, MA: Harvard University Press, 1989; e David Wellbery (ed.), A New History of German Literature. Cambridge, MA: Harvard University Press, 2004.
Agora, se a minha impressão estiver correta — a de que o que muitos de nós buscamos na historicidade da literatura, nas condições epistemológicas contemporâneas, é um (vislumbre do) sentimento sensorial de pertencer e de se inscrever no mundo material que nos cerca -, então essa função está tão distante quanto se possa imaginar da tarefa que as primeiras histórias das literaturas nacionais quiseram desempenhar, isto é, da tarefa - muito hegeliana - de desenvolver, por meio de uma narrativa ampliada, a imagem e o conceito de uma nação. Em que um número crescente de leitores e acadêmicos parece estar interessado atualmente, mais do que em concepções de identidades coletivas, é, para dizer uma última vez, no sentimento pontual de ser inscrito no mundo (não apenas) material. Como isso é um sentimento pontual, um sentimento que deve ser localizado e estabelecido em cada caso específico, eu o associo fortemente com um novo tipo de história literária que é fragmentada em centenas de pequenas "entradas". Pois essa densa contextualização histórica traz de volta à vida e à presença o que chamamos de "eventos literários", ao passo que essas curtas "entradas" usam textos literários para evocar mundos do passado - mas elas não convergem em nenhum conceito amplo que tente capturar a identidade de uma nação. ${ }^{23}$

Evidentemente, não estou afirmando que essa é a única forma de vivenciar a historicidade específica da literatura nas condições epistemológicas contemporâneas. Também imagino, por exemplo, que, no meio de nosso presente amplo, textos literários canonizados podem se tornar pontos de concentração porque, como buracos negros na física, eles absorveram e agora carregam consigo muitas camadas historicamente diferentes de interpretação e recepção. Mais do que retraduzir essas condensações de camadas de sentido em narrativas da história da recepção, textos clássicos, como "buracos negros" de sentidos passados, poderiam se tornar o lugar para ainda outro tipo e dimensão de historicidade.

Como a concretude da literatura e os textos literários como buracos negros de sentidos, como essas novas formas de vivenciar a historicidade da literatura podem se relacionar uma com as outras - eu não sei. Eu não tenho um plano diretor ou um programa para o futuro da história literária. Como disse no início: sequer estou seguro sobre se esse futuro virá a existir. Teremos que pensar, experimentar e esperar - se tivermos interesse em continuar escrevendo histórias da literatura. A única coisa que eu acredito ser certa é que não encontraremos quaisquer soluções pré-fabricadas para nossos problemas nos trabalhos de nossos grandes predecessores. Nem mesmo nos trabalhos de heróis como Erich Auerbach ou Walter Benjamin, pois eles também viveram sob condições epistemológicas que já não são as nossas. 
HANS ULRICH “SEPP” GUMBRECHT (1948) - Intelectual alemão natural de Wurtzburgo e que produziu obras de imensa repercussão internacional nos campos da filosofia, filologia e estética, além de teoria, crítica e historiografia literárias. Dentre as suas maiores contribuições teóricas se destacam certamente os conceitos de Stimmung (termo de difícil tradução, que pode ser entendido como Atmosfera ou Ambiência) e a proposta de um componente de Presença no contato humano com o mundo que, em tensão com o componente de Sentido, constituiria a experiência estética. Gumbrecht recebeu títulos de doutor honoris causa em universidades de diversos países, desde o Canadá até a Alemanha, Rússia, Portugal, Geórgia, Hungria e Dinamarca. Foi professor na Universidade de Bochum e na Universidade de Siegen, na Alemanha, antes de ocupar a cadeira Albert Guérard de Literatura na Universidade de Stanford, em 1989, onde atualmente é professor emérito. Gumbrecht tem inúmeros livros publicados em diversos países; dentre os traduzidos ao português brasileiro, destacam-se Atmosfera, Ambiência, Stimmung: Sobre um potencial oculto da literatura (2014, Contraponto \& PUC-RJ) e Produção de Presença: O que o sentido não consegue transmitir (2016, Contraponto \& PUC-RJ). Está atualmente trabalhando em seu novo livro, com título provisório de Prose of the World: Diderot, Goya, Lichtenberg, and Mozart and an End of Enlightenment.

CAIO CESAR ESTEVES DE SOUZA - Mestre em letras pela FFLCH-USP, com dissertação sobre a poesia atribuída a Alvarenga Peixoto. Trabalha na edição da poesia completa do autor, a ser publicada pela Editora Perspectiva em parceria com a Biblioteca Brasiliana Guita e José Mindlin da USP. 